\title{
Adenoid Cystic Carcinoma of Palate-A Difficult Diagnosis
}

\author{
SMA SADAT $^{\mathrm{a}}$, MS ISLAM ${ }^{\mathrm{b}}, \mathrm{MS} \mathrm{HOSSAIN}^{\mathrm{c}}$, M AHMED $^{\mathrm{d}}, \mathrm{SA} \mathrm{RUPA}^{\mathrm{e}}$
}

\begin{abstract}
A 41- year-old man presented with gradually increasing swelling in right side of palate for last 10 months. Though initially painless, later on he felt pain within the swelling which was localized and dull intermittent in nature without relation to eating, drinking or chewing and gradually was radiating to right forehead and bellow right orbit for last 5 months.
\end{abstract}

Examination revealed paresthesia in the right infraorbital region, lateral wall of the nose and right half of the upper lipand right incisors, canine and premolar teeth.There was a well-defined, oval shaped, firm, non-tender, smooth surfaced swelling without any surface ulceration measuring $3 \mathrm{~cm} \mathrm{X} 2$ cmat right side of the palate. Neck examination showed no lymphadenopathy.

(J Bangladesh Coll Phys Surg 2021; 39: 142-144)

DOI: https://doi.org/10.3329/jbcps.v39i2.52395

a. Dr. S. M. Anwar Sadat, BDS, MCPS, FCPS, MS (OMS), Associate Professor, Dept of Oral \& Maxillofacial Surgery, Dhaka Dental College, Dhaka, Bangladesh, Consultant (Part Time), Square Hospitals Ltd, Dhaka, Bangladesh

b. Dr. Md. Shahadul Islam, BDS, FCPS Trainee (OMS), Assistant Registrar, Dept of Oral \& Maxillofacial Surgery, Dhaka Dental College, Dhaka

c. Dr.Md. Sanwar Hossain, BDS, FCPS Trainee (OMS), Hon Medical Officer, Dept of Oral \& Maxillofacial Surgery, Dhaka Dental College, Dhaka

d. Dr. Mousumi Ahmed, MBBS, FCPS (Histopathology), Associate Professor, Dept of Histopathology and Cytology, BIRDEM General Hospital, Dhaka

e. Dr. Sharmin Akhtar Rupa, MBBS, M. Phil, FCPS, Associate Professor, Dept of Radiology and Imaging, Popular Medical College and Hospital, Dhaka

Address correspondence to: Dr. S. M. Anwar Sadat, BDS, MCPS, FCPS, MS (OMS), Associate Professor, Dept of Oral \& Maxillofacial Surgery, Dhaka Dental College, Dhaka, Bangladesh. Consultant (Part Time), Square Hospitals Ltd, Dhaka, Bangladesh, E-mail: an_sadat@yahoo.com, Cell: +8801711156023
Extra oral examination revealed no swelling, Paresthesia in the right infraorbital region, lateral wall of the nose and right half of the upper lipand right incisors, canine and premolar teeth was evident.There was a well-defined, oval shaped, firm, non-tender, smooth surfaced swelling without any surface ulceration measuring $3 \mathrm{~cm} \mathrm{X} 2$ cmat right side of the palate near molar teeth (Image 1). Neck examination showed non remarkable bilateral submandibular lymphadenopathy.

FNAC reported benign epithelial cells arranged in groups and strips of stromal tissue in a background of blood without having evidence of malignant cell.Computed Tomography showed focal bony erosion with overlying soft tissue thickening at hard palate (Image 2).

Clinical and CT scan findings were conflicting with the FNAC report and soincision biopsy was done which revealed stromal tissue with minor salivary gland and also composed of anaplastic cells having moderate to scanty cytoplasm \& round to oval nuclei. Cells are arranged in cribriform pattern and tubules and there is presence of perineural invasion suggestive of adenoid cystic carcinoma (Image 3). These findings are usual typical histologic features of adenoid cystic carcinoma ${ }^{1}$.

Though the CT scan showed small lesion in the palate without any extension into the maxillary sinus, clinical feature with pain in the lesion with radiation to cranium and paresthesia in maxillary nerve distribution area and histological features of adenoid cystic carcinoma with peri neural invasion, we suspected the spreading of tumor to the intra cranial structures causing features of pain and Paresthesia. Magnetic Resonance Imaging can diagnose effectively intracranial extention of adenoid cystic carcinoma of palate ${ }^{2,3,4}$. So MRI was suggested for confirmation which showed homogenously enhancing mass ( $31 \mathrm{~mm} \mathrm{X} 22 \mathrm{~mm}$ ) on the right side of palate, $4 \mathrm{~mm}$ away from the midline where erosion of adjacent bone was seen. The mass extends along 
the V2nerve (maxillary division of trigeminal nerve) in pterygopalatine fossa with intracranial extension through foramen rotundum (Image 4 and 5).

Though the lesion was small, due to intra cranial extension, tumor board decided and treated patient by chemoradiation. Patient is under follow up of both maxillofacial and oncology departments. This report emphasizes the importance of meticulous clinical and MRI evaluation of any suspected malignant palatal mass before deciding surgical treatment.

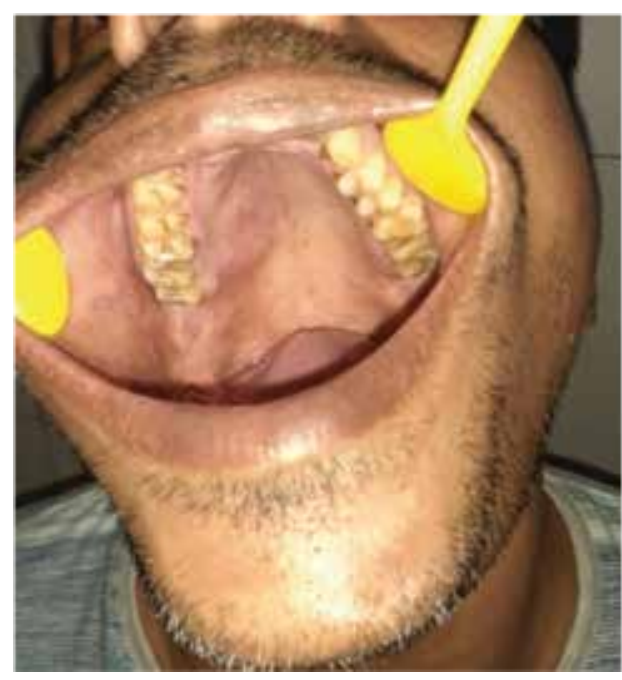

Image 1: Well-defined, oval shaped, smooth surfaced swelling without any surface ulcerationat right side of the palate near molar teeth.

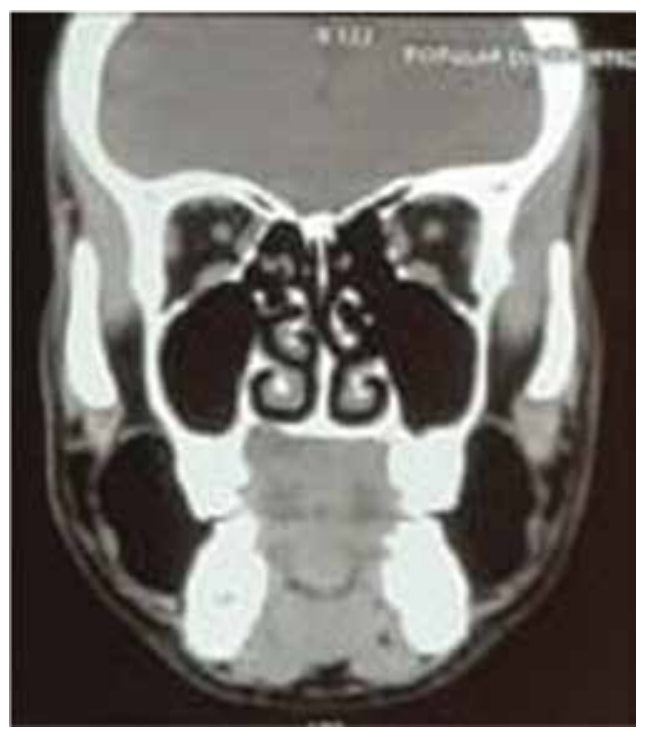

Image 2: Computed Tomography axial view showsfocal bony erosion with overlying soft tissue thickeningin right hard palate and adjacent alveolar process.

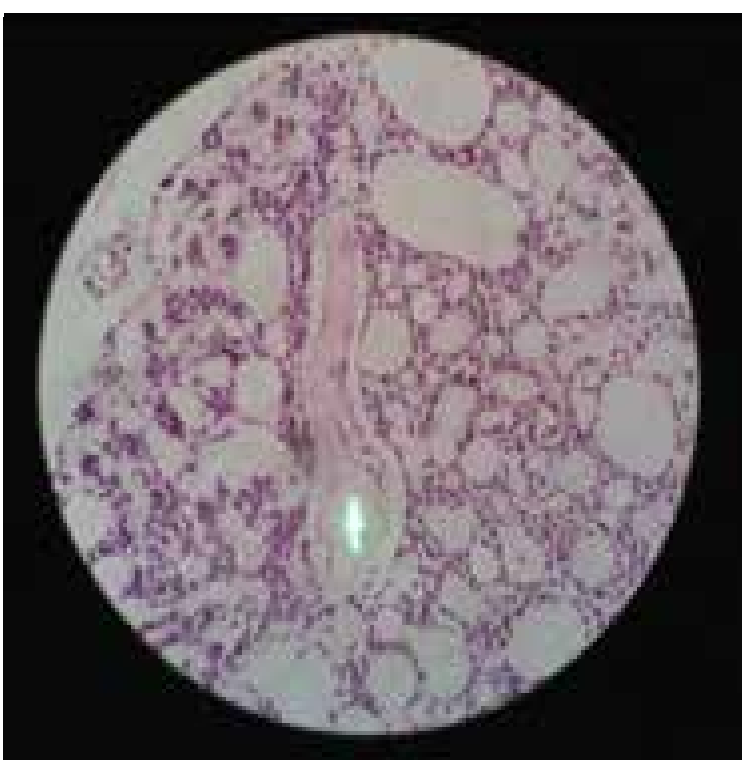

Image 3: Microscopic picture showing perineural invasion in adenoid cystic carcinoma. Arrow is indicating nerve fibers. (40X10)

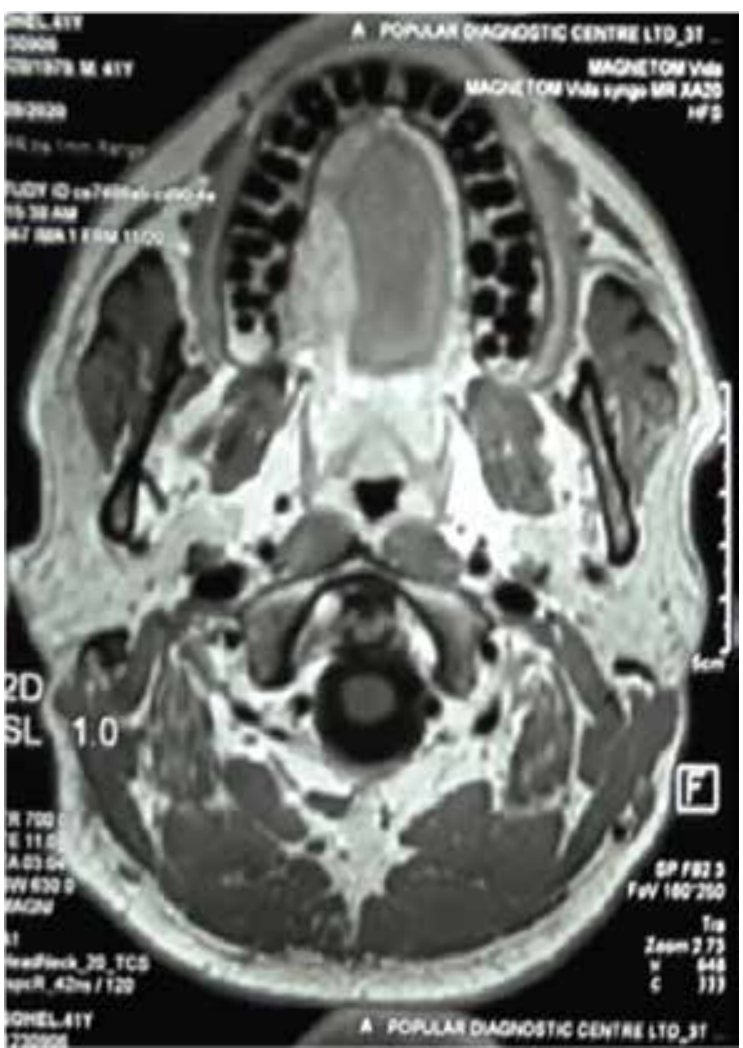

Image 4: Post contrast axial image shows homogenously enhancing mass on right side of the palate 


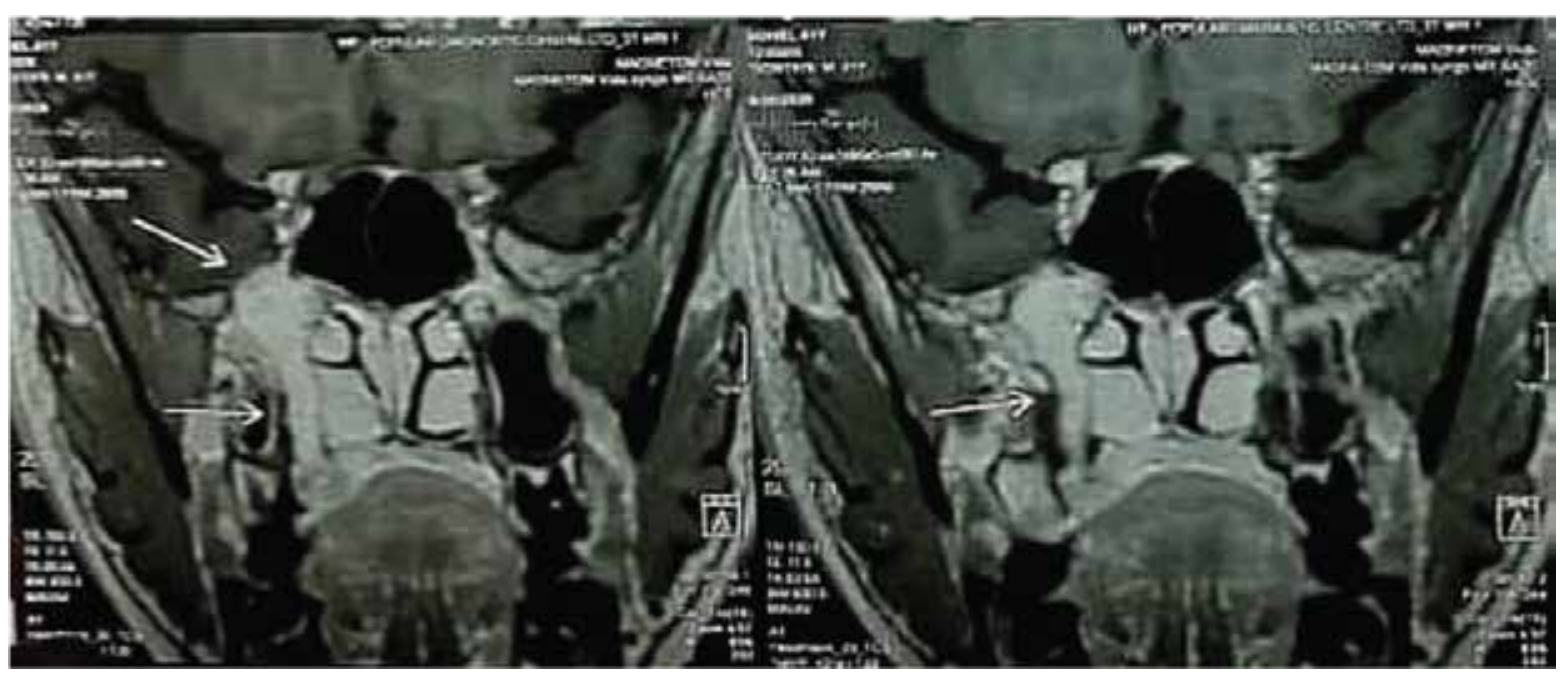

Image 5: T1 Weighted post contrast coronal image shows enhancing mass at right side of the palate with moderate enhancement and asymmetrical enlargement of ipsilateral maxillary division of trigeminal nerve (V2 nerve) extends from the mass through the foramen rotundum into the intra cranial cavity.

\section{References}

1. Yaga US, Gollamudi N, Mengji AK, Mengji AK, Besta R, Panta P, Prakash B, Rajashekar E. Adenoid cystic carcinoma of the palate: case report and review of literature. Pan African Medical Journal 2016; 24(1). http://doi.org/ 10.11604/pamj.2016.24.106.8596

2. Hanna E, Vural E, Prokopakis E. The sensitivity and specificity of High Resolution Imaging in evaluating perineural spread of adenoid cystic carcinoma to the skull base. Arch Otolaryngol Head Neck Surg 2007;133(6):541-545. http://doi.org/10.1001/archotol.133.6.541
3. R Sigal, O Monnet, $\mathrm{T}$ de Baere, C Micheau, L G Shapeero, M Julieron, J Bosq, D Vanel, J D Piekarski, B Luboinski. Adenoid cystic carcinoma of the head and neck: evaluation with MR imaging and clinical-pathologic correlation in 27 patients. Radiology 1992;184(1). https://doi.org/10.1148/radiology.184.1.1319079

4. Laine FJ, Braun IF, Jensen ME, Nadel L, Som PM. Perineural tumor extension through the foramen ovale: evaluation with MR imaging.Radiology 1990;174(1). https://doi.org/ 10.1148/radiology.174.1.2152985 